Ciência Florestal, Santa Maria, v. 20, n. 4, p. 657-664, out.-dez., 2010

ISSN 0103-9954

\title{
EFEITO DA RADIAÇÃO ULTRAVIOLETA NA COR DA MADEIRA DE FREIJÓ (Cordia goeldiana Huber) APÓS RECEBER PRODUTOS DE ACABAMENTOS
}

\author{
EFFECT OF ULTRAVIOLET RADIATION ON THE COLOR OF FREIJÓ WOOD \\ (Cordia goeldiana Huber) AFTER APPLICATION OF FINISHING PRODUCTS
}

\author{
Joaquim Carlos Gonçalez ${ }^{1}$ Tiago Leandro Freire Félix ${ }^{2}$ Fernando Nunes Gouveia ${ }^{3}$ \\ José Arlete Alves Camargos ${ }^{4}$ Patrícia Gomes Ribeiro ${ }^{5}$
}

\begin{abstract}
RESUMO
A radiação ultravioleta é considerada a mais prejudicial ao uso da madeira afetando suas propriedades, sobretudo a sua cor superficial. A aplicação de produtos de acabamentos, como os vernizes, os stains, as tintas, podem minimizar a atuação dessa radiação. Este trabalho teve como objetivo avaliar o efeito da radiação ultravioleta, relativo ao envelhecimento artificial acelerado, na coloração da madeira de freijó (Cordia goeldiana Huber) tratadas com polisten e seladora (nitrocelulose), com monitoramento por meio de um espectrocolorimetrico. As amostras da madeira foram submetidas a ciclos de radiação ultravioleta em um reator fotoquímico, em tempos de 84 e 168 horas. Os parâmetros colorimétricos ( $L^{*}, a^{*}, b^{*} C$ e h*) foram medidos antes a após os tratamentos. $O$ tratamento com polisten foi o que ofereceu maior proteção às radiações ultravioletas, dando uma maior estabilidade aos parâmetros. O tratamento com seladora foi o que apresentou uma maior alteração da cor após a simulação de envelhecimento no reator fotoquímico.
\end{abstract}

Palavras-chave: fotodegradação; espécie; nitrocelulose; polisten.

\begin{abstract}
Ultraviolet radiation is considered the most damaging radiation to wood, affecting its properties and especially its color. The application of finishing products such as varnishes, stains and inks can minimize the action of this radiation. This study aimed to evaluate the effect of ultraviolet radiation, through artificially accelerated aging, on the color of freijó wood (Cordia goeldiana Huber) treated with "polisten" and sealer (nitrocellulose), by means of spectrocolorimetric tracking. The samples of wood were subjected to cycles of ultraviolet radiation in a photochemical reactor for 84 and 168 hours. The colorimetric parameters $\left(L^{*}, a^{*}, b^{*}, C, h^{*}\right)$ were measured before and after the treatments. The treatment with "polisten" offered greater protection against ultraviolet radiation, yielding greater stability to the parameters. The treatment with sealer led to a greater change in color after the simulation of aging in the photochemical reactor.
\end{abstract}

Keywords: photodegradation; species; nitrocellulose; polisten.

1. Engenheiro Florestal, Dr., Professor Associado do Departamento de Engenharia Florestal, Universidade de Brasília, Campus Universitário Darcy Ribeiro, Asa Norte, CEP 70919-900, Brasília (DF). goncalez@unb.br

2. Engenheiro Florestal, Professor do Departamento de Engenharia Florestal, Universidade de Brasília, Campus Universitário Darcy Ribeiro, Asa Norte, CEP 70919-900, Brasília (DF). tiagoag2@hotmail.com

3. Engenheiro Florestal, Dr., Pesquisador do Laboratório de Produtos Florestais, Serviço Florestal Brasileiro, CEP 70919-900, Brasília (DF). fernando.gouveia@ibama.gov.br

4. Admistrador de Empresa, M.Sc., Pesquisador do Laboratório de Produtos Florestais, Serviço Florestal Brasileiro, CEP 70919-900, Brasília (DF). jose.camargos@ibama.gov.br

5. Engenheira Florestal, M.Sc., Doutorando em Ciências Florestais pelo Departamento de Engenharia Florestal, Universidade de Brasília, Campus Universitário Darcy Ribeiro, Asa Norte, CEP 70919-900, Brasília (DF). patriciagomesribeiro@gmail.com

Recebido para publicação em 12/03/2009 e aceito em 20/06/2010

Ci. Fl., v. 20, n. 4, out.-dez., 2010 


\section{INTRODUÇÃO}

A cor da maioria das espécies de madeira mostra-se instável em condições naturais, podendo ser alterada por diversos fatores, tais como: raios solares, temperatura, teor de umidade, reações químicas de foto-oxidação e ações por organismos xilófagos. Essa instabilidade está relacionada diretamente aos constituintes da madeira (componentes químicos, anatômicos entre outros) que exercem grande influência na formação da cor.

Os principais fatores que contribuem para a degradação natural da madeira são: umidade, luz, forças mecânicas e calor; que podem atuar isoladamente ou de forma combinada. A peça de madeira exposta à luz absorve intensamente a radiação solar e sofre degradação fotoquímica por causa da ação dos raios ultravioletas, que comprometem o seu aspecto geral, tornando-a descorada ou acinzentada, amarelada ou escurecida, dependendo da influência da composição da madeira, especialmente dos extrativos (AYADI et al., 2003; FEIST, 1983, CHANG et al., 1982).

A madeira exposta à radiação solar está sujeita à degradação de sua superfície. Primeiramente, ocorre uma mudança de cor e depois uma perda de suas propriedades mecânicas.

Segundo Hon (2001), citado por Silva e Pastore (2004), o intemperismo é uma combinação complexa da ação do sol, da chuva ou da umidade e dos ventos que ocorrem até $2,5 \mathrm{~mm}$ abaixo da superfície externa da madeira. Desses fatores, o processo de decomposição em conseqüência da radiação ultravioleta (UV) presente na luz do sol é o mais prejudicial, pois dá início a modificações químicas dos principais polímeros que constituem a madeira: a celulose, a lignina, e a hemicelulose.

A descoloração da madeira exposta à luz solar ocorre por causa da modificação de grupos cromóforos capazes de absorver a radiação ultravioleta no comprimento de onda entre 300 e $400 \mathrm{~nm}$ (TEMIZ, et al., 2005). A exposição à luz causa modificações anatômicas (CHANG et al., 1982). Em períodos longos de exposição, é possível observar uma mudança nas propriedades viscoelásticas da madeira (GEORGE et al., 2005).

Existem registros históricos que indicam que mesmo após 100 anos de exposição contínua à luz, a madeira é erodida em não mais que sete milímetros (CHANG et al., 1982).

A fotodegradação da madeira é um fenômeno superficial, pela grande quantidade de grupos (carbonila, dupla ligação, hidroxila fenólica...) ou sistemas cromóforos (quinonas, bifenil...) dos componentes distribuídos na camada externa que impedem a entrada de luz na madeira. A radiação ultravioleta consegue penetrar até uma profundidade de $75 \mu \mathrm{m}$ e a visível atinge cerca de 200 $\mu \mathrm{m}$, dependendo da cor original da madeira. Apesar da radiação visível penetrar mais profundamente, sua energia (inferior a $70 \mathrm{Kcal} / \mathrm{mol}$ ) é insuficiente para romper as ligações químicas de qualquer um dos constituintes da madeira (HON, 2001 citado por PASTORE, 2004). Por isso a radiação ultravioleta é considerada a mais danosa ao uso da madeira.

Há diversas formas de prevenir à madeira da fotodegradação, como a aplicação de compostos químicos inorgânicos, a aplicação de produtos de acabamento como vernizes, stains e tintas, que embora forneçam algum tipo de proteção podem alterar $o$ aspecto natural da madeira.

Para reduzir os custos e o tempo de duração dos testes em campo, para a avaliação do intemperismo, foram desenvolvidos ensaios de laboratório que simulam o intemperismo e permitem estimar e comparar a durabilidade natural das madeiras de diversas espécies (Oliveira et al., 1986). O processo de incidência de raios ultravioletas (UV) pode ser simulado através de um reator fotoquímico. Os reatores fotoquímicos podem ser classificados quanto à fonte de radiação, que pode ser solar ou artificial (utilizando uma lâmpada de luz ultravioleta, por exemplo). As fontes artificiais de radiação mais comum para tais reatores fotoquímicos são as lâmpadas de vapor de mercúrio de baixa, média ou alta pressão, todas com emissão de luz UV. Essas lâmpadas usualmente são dispostas de forma que as amostras a serem tratadas recebam a maior concentração de fótons possível. Para isso, muitos reatores utilizam lacas espelhadas refletoras, ou mesmo são construídos de forma cilíndrica com suas paredes internas de material refletor (NEUMANN e QUINA, 2002).

A madeira de freijó é usada no Brasil, em especial pelos segmentos moveleiros e de divisórias. As instituições públicas e privadas, sobretudo no Distrito Federal, fazem dessa espécie a principal fonte de matéria-prima para compor seus mobiliários. Com o passar dos anos, a maioria das madeiras tendem a escurecer. É comum ocorrer nessas instituições o embate entre fornecedores e a instituição quando há a aquisição de divisórias e móveis, pois observa-se nestas, a coloração diferente às existentes no local. 
O objetivo deste trabalho foi o de avaliar o efeito da radiação ultravioleta, durante $o$ envelhecimento artificial acelerado, na coloração da madeira de freijó (Cordia goeldiana Huber) antes e após aplicação de produtos de acabamentos.

\section{MATERIAL E MÉTODOS}

Esta pesquisa foi desenvolvida na Universidade de Brasília - UnB e no Laboratório de Produto Florestais - LPF/SFB.

\section{Preparação das amostras}

No mercado de Brasília DF, foram adquiridas três pranchas de madeira de freijó (Cordia goeldiana Huber). Essa madeira foi identificada, por meio de análise anatômica, para comprovação da espécie. De cada prancha confeccionaram-se cinquenta amostras nas dimensões de $8,0 \mathrm{~cm}$ de comprimento, $3,0 \mathrm{~cm}$ de largura e $0,5 \mathrm{~cm}$ de espessura, retiradas no sentido tangencial da madeira. As amostras foram deixadas em uma sala de climatização para atingir o teor de umidade médio de $12 \%$.

Ao acaso, tomaram-se 12 amostras para realização da pesquisa, sendo que quatro delas não receberam produtos de acabamentos e serviram como testemunhas, quatro foram tratadas com seladora (NL 924500 Sayarlack) e as quatro restantes foram tratadas com polisten (Stain impregnante transparente Sayarlack). Assim o experimento foi conduzido com dois tratamentos (tratamento 1 - polisten e tratamento 2 - seladora) além da testemunha. Os dois produtos de acabamentos utilizados são comumente empregados pelas indústrias de mobiliarios e divisórias.

\section{Medição da Cor e Envelhecimento Artificial Acelerado}

As amostras foram submetidas a uma sequência de lixas de granas 120, 220 e 320 para receberem os produtos de acabamento mencionados. Em seguida, fez-se a primeira medida colorimétrica $\left(L^{*}, a^{*}, b^{*}, C\right.$ e h*) em cada uma das 12 amostras. $\mathrm{Na}$ sequência, as amostras foram tratadas com os produtos de acabamento (polisten e seladora), seguindo os procedimentos: após lixadas, aplicouse a primeira demão do produto desejado (polisten ou seladora) e esperou-se secar. Novamente, as amostras foram lixadas para a aplicação da segunda demão do produto de acabamento. Após secas, as amostras foram novamente lixadas e finalmente aplicou-se a terceira e última demão do produto, sistema usual empregado pelas indústrias do segmento moveleiro. Após tais procedimentos, realizou-se a segunda medição colorimétrica $\left(\mathrm{L}^{*}\right.$, $a^{*}, b^{*}, C$ e h*).

As medições dos parâmetros colorimétricos $\left(L^{*}, a^{*}, b^{*}, C\right.$ e $\left.h^{*}\right)$ foram feitas em um espectrocolorímetro Datacolor Microflash 200d conectado a um microcomputador, com iluminante D65, e angulo standart de $10^{\circ}$.

A seguir, as 12 amostras foram levadas ao reatorfotoquímicoparasimulaçãodoenvelhecimento artificial acelerado, onde permaneceram por 84 horas. Para simular o efeito da radiação ultravioleta na superfície da madeira, utilizou-se um reator fotoquímico Rayonet com 12 lâmpadas UV, cada uma com $8 \mathrm{~W}$, as quais emitem radiação no comprimento de onda de 350 nanômetros. De acordo com Chang e Chang (2001), o envelhecimento artificial nestas condições, correspondente a um ano de exposição em um ambiente de escritório. Após esta simulação, as amostras foram retiradas do reator fotoquímico, fazendo-se a terceira medição colorimétrica. Em seguida, essas amostras retornaram ao reator por mais 84 horas para a simulação de mais um período de envelhecimento, totalizando 168 horas. Finalmente, as amostras foram retiradas do reator fotoquímico e realizadas as medições colorimétricas.

Para as análises colorimétricas, foram realizadas vinte medidas ao longo de cada amostra da madeira. Esse número de medidas foi baseado em testes prévios no qual foi realizada a determinação da cor da madeira, fazendo-se de uma a vinte medidas por amostra, constatando-se que a variância da cor da madeira torna-se praticamente constante acima das dez medições. Em todas as amostras, a medição dos parâmetros colorimétricos, antes, depois da aplicação dos produtos e após o envelhecimento acelerado foi realizada nos mesmos locais.

No interior do reator, as amostras foram fixadas em um carrossel, com a face tangencial expostas à ação da luz, distante em aproximadamente dois centímetros. Empregou-se um ventilador interno com o propósito de evitar o superaquecimento no interior da câmara do reator fotoquímico.

Para mensurar a alteração na cor da madeira antes e após os tratamentos $(\Delta \mathrm{E})$, foi utilizada a metodologia adotada por diversos autores (Silva et al., 2007, Mitsui e Tsuchikawa, 2005, Pastore et al., 2004, Chang \& Chang, 2001), que é calculada pela 
diferença entre os parâmetros obtidos das amostras antes e após o procedimento de envelhecimento, como mostra a equação a seguir:

$$
\Delta E=\sqrt{\Delta L^{2}+\Delta a^{2}+\Delta b^{2}}
$$

Em que: $L^{*}$ : claridade ; $a^{*}$ : matizes do eixo vermelho ${ }^{(+a)}-\operatorname{verde}^{(-a)} ; b^{*}$ : matizes do eixo amarelo $^{(+b)}-$ azul $^{(-b)}$.

Para as demais análises estatísticas usouse o programa Genes: aplicativo computacional em genética e estatística, permitindo-se fazer ANOVAe Teste de Tukey.

\section{RESULTADOS E DISCUSSÃO}

A Tabela 1 mostra os valores médios dos parâmetros colorimétricos ( $\mathrm{L}^{*}, \mathrm{a}^{*}, \mathrm{~b}^{*}, \mathrm{C}$ e h*) das amostras de madeira de freijó (Cordia goeldiana) antes e após receber os produtos de acabamento (polisten e seladora).

Com base na classificação proposta por Camargos (1999), a madeira de freijó possui uma coloração oliva-claro, caracterizada, sobretudo, pela claridade $\left(\mathrm{L}^{*}\right)$ e pela coordenada $\mathrm{b}^{*}$, responsável pela coloração amarela. O ângulo de tinta $\mathrm{h}$ * contribui para essa afirmativa posicionando a madeira dessa espécie, próximo ao eixo amarelo, conforme o sistema CIELAB 1976.

Verifica-se ainda que os desvios-padrão, de forma geral, são bem-homogêneos, mostrando a uniformidade das amostras tanto da testemunha como as dos tratamentos com polisten e seladora.

Ao aplicar os produtos polisten e seladora nas amostras verificou-se uma alteração de suas cores (escurecimento), diminuindo-se os valores da claridade $\left(\mathrm{L}^{*}\right)$ e aumentando os valores da coordenada a* (responsável pela cor vermelha). É interessante observar que a coordenada $b^{*}$, em ambos os casos, também aumentou, sugerindo que os produtos aplicados possuem pigmento amarelo ou interagem com a madeira havendo a formação deste. Analisando os dois produtos aplicados, verificase que o polisten escurece mais a madeira em um primeiro momento, pois o valor de $\mathrm{L}^{*}$ é menor e o das coordenadas $\mathrm{a}^{*} \mathrm{e} \mathrm{b}^{*}$ são maiores, em relação às amostras tratadas com seladora. $\mathrm{O}$ ângulo de tinta (h*) mostra claramente essa situação, posicionando as amostras que receberam o produto polisten mais próxima ao eixo vermelho.

Após a madeira de freijó ser submetida à radiação ultravioleta no reator fotoquímico por períodos de 84 horas e 168 horas, constatou-se alterações em sua cor. Aplicou-se um teste de análise de variância (ANOVA) para verificar a possibilidade de existência de diferenças entre os tratamentos (testemunha, polisten e seladora) submetidas a essas radiações. Segundo Temiz, et al. (2005), a descoloração da madeira (testemunha) exposta à radiação ultravioleta ocorre por causa da modificação de grupos cromóforos capazes de absorver esta radiação no comprimento de onda entre 300 e $400 \mathrm{~nm}$.

Em uma primeira análise observa-se que o

TABELA 1: Valores médios e desvio-padrão dos parâmetros colorimétricos das amostras de madeira naturais e após o tratamento com polisten e seladora.

TABLE 1: Mean values and standard deviation of colorimetric parameters of samples of natural wood before and after treatment with polisten and sealer.

\begin{tabular}{|c|c|c|c|c|c|c|c|c|c|c|c|}
\hline \multirow{2}{*}{ Tratamentos } & \multirow{2}{*}{ Estatística } & \multicolumn{5}{|c|}{ Madeira sem tratamentos (natural) } & \multicolumn{5}{|c|}{ Madeira após aplicação dos produtos } \\
\hline & & $\mathrm{L}^{*}$ & $a^{*}$ & $b^{*}$ & $\mathrm{C}$ & $\mathrm{h}^{*}$ & $\mathrm{~L}^{*}$ & $a^{*}$ & $b^{*}$ & $\mathrm{C}$ & $\mathrm{h}^{*}$ \\
\hline \multirow{2}{*}{ Testemunha } & Média & 72,00 & 6,05 & 23,10 & 23,88 & 75,32 & -- & -- & -- & -- & -- \\
\hline & Desvio-padrão & 2,01 & 0,27 & 0,84 & 0,83 & 0,74 & -- & -- & -- & -- & -- \\
\hline \multirow{2}{*}{ Polisten } & Média $^{1}$ & $72,07 \mathrm{~A}$ & $6,28 \mathrm{~A}$ & $23,05^{\mathrm{a}}$ & $23,90 \mathrm{~A}$ & $74,77 \mathrm{~A}$ & $47,90 \mathrm{~B}$ & $19,48 \mathrm{~B}$ & $34,22 \mathrm{~B}$ & $39,39 \mathrm{~B}$ & $60,23 \mathrm{~B}$ \\
\hline & Desvio-padrão & 4,08 & 0,82 & 0,51 & 0,52 & 1,95 & 2,32 & 0,99 & 3,32 & 3,27 & 1,72 \\
\hline \multirow{2}{*}{ Seladora } & Média $^{1}$ & $72,21 \mathrm{~A}$ & $5,82 \mathrm{~A}$ & $22,97^{\mathrm{a}}$ & $23,69 \mathrm{~A}$ & $75,78 \mathrm{~A}$ & $59,44 \mathrm{~B}$ & $10,19 \mathrm{~B}$ & $30,31 \mathrm{~B}$ & $31,98 \mathrm{~B}$ & $71,41 \mathrm{~B}$ \\
\hline & Desvio-padrão & 1,18 & 0,28 & 0,82 & 0,83 & 0,60 & 1,33 & 0,37 & 0,87 & 0,84 & 0,79 \\
\hline
\end{tabular}

Em que: ${ }^{1}$ Os valores assinalados com a mesma letra, na mesma linha, dentro de cada parâmetro colorimétrico, para cada tratamento (natural e com produtos), não diferem entre si ao nível de 1\% de significância pelo teste de Tukey.

Ci. Fl., v. 20, n. 4, out.-dez., 2010 
coeficiente de variação foi baixo, mostrando uma alta precisão do experimento. Essa análise também mostra que existem diferenças significativas entre as variáveis colorimétricas dos tratamentos estudados, após as radiações ultravioletas efetuadas. Foi constatada uma alta correlação entre os parâmetros nos três tratamentos. Verificou-se que os parâmetros $L^{*}$ e a* são diretamente proporcionais, enquanto esses são inversamente proporcionais com os parâmetros b*, C e h*.

A Tabela 2 apresenta os valores médios dos parâmetros colorimétricos dentro de cada tratamento submetidos a radiações ultravioletas, além da testemunha.

Observando-se os parâmetros colorimétricos dos tratamentos submetidos a diferentes períodos de radiações ultravioletas, constata-se que estes apresentam semelhança de comportamento entre os tratamentos seladora e testemunha. Isto é, o envelhecimento artificial (84 e 168 horas) levou a uma diminuição significativa da claridade $\left(\mathrm{L}^{*}\right)$ da madeira, ocorrendo um escurecimento desta, com consequentes aumentos significativos da coloração vermelha (representada pela coordenada a*). Esse efeito foi mais marcante para a seladora, pois os valores dos parâmetros colorimétricos confirmaram um escurecimento mais pronunciado da cor para essas amostras. Provavelmente o produto possui em sua composição elementos de cor mais escura e ou que interagem com os componentes da madeira levando a um escurecimento mais marcante das amostras que receberam tal produto. Uma análise mais aprofundada tanto dos constituintes químicos da madeira como do produto de acabamento poderia ajudar a esclarecer melhor o fato ocorrido. Um acompanhamento pela análise de infravermelho pode mostrar quais grupos cromóforos estão presentes e como estes são alterados

\section{Refletância}

As figuras de 1 a 3 colaboram com os resultados da tabela 2, mostrando as curvas de refletância da testemunha e dos tratamentos seladora e polisten nos diversos tempos de radiações ultravioletas. As alterações dos parâmetros colorimétricos significam que a incidência de radiação ultravioleta provocou modificações nas superfícies das madeiras. Nota-se que tanto nas amostras testemunhas (figura 1) quanto nas tratadas com seladora (figura 2) não houve diferenças marcantes na refletância entre 84 e 168 horas como as ocorridas entre 0 e 84 horas. Isso se deve ao fato da mudança de cor ocorrer mais rapidamente nas madeiras nas primeiras horas expostas à radiação ultravioleta. Tal constatação também foi feita por Tolvaj (1994) estudando 16 espécies de madeiras temperadas.

TABELA 2: Valores médios dos parâmetros colorimétricos dentro de cada tratamento submetidos a radiações ultravioletas e a testemunha.

TABLE 2: Mean values of the colorimetric parameters within each treatment subjected to ultraviolet radiation and the control.

\begin{tabular}{ccccccc}
\hline \multirow{2}{*}{ Tratamentos } & $\begin{array}{c}\text { Radiação ultravioleta } \\
\text { (horas) }\end{array}$ & \multicolumn{5}{c}{ Parâmetros Colorimétricos } \\
\cline { 2 - 7 } & $0^{1}$ & $72,00 \mathrm{~A}$ & $6,05 \mathrm{~A}$ & $23,10 \mathrm{~A}$ & $23,88 \mathrm{~A}$ & $75,31 \mathrm{~A}$ \\
\multirow{3}{*}{ Testemunha } & 84 & $67,15 \mathrm{~B}$ & $9,04 \mathrm{~B}$ & $29,04 \mathrm{~B}$ & $30,42 \mathrm{~B}$ & $72,71 \mathrm{~B}$ \\
& 168 & $66,10 \mathrm{C}$ & $9,69 \mathrm{C}$ & $29,05 \mathrm{~B}$ & $30,63 \mathrm{~B}$ & $71,53 \mathrm{C}$ \\
\hline \multirow{3}{*}{ Polisten } & $0^{1}$ & $47,90 \mathrm{~A}$ & $19,48 \mathrm{~A}$ & $34,22 \mathrm{~A}$ & $39,39 \mathrm{~A}$ & $60,23 \mathrm{~A}$ \\
& 84 & $48,30 \mathrm{~A}$ & $19,33 \mathrm{~A}$ & $34,01 \mathrm{~A}$ & $39,13 \mathrm{~A}$ & $60,28 \mathrm{~A}$ \\
& 168 & $47,98 \mathrm{~A}$ & $19,33 \mathrm{~A}$ & $33,38 \mathrm{~A}$ & $38,58 \mathrm{~A}$ & $59,82 \mathrm{~A}$ \\
\hline \multirow{3}{*}{ Seladora } & $0^{1}$ & $59,44 \mathrm{~A}$ & $10,19 \mathrm{~A}$ & $30,31 \mathrm{~A}$ & $31,98 \mathrm{~A}$ & $71,41 \mathrm{~A}$ \\
& 84 & $52,61 \mathrm{~B}$ & $14,52 \mathrm{~B}$ & $32,87 \mathrm{~B}$ & $35,96 \mathrm{~B}$ & $66,17 \mathrm{~B}$ \\
& 168 & $50,88 \mathrm{C}$ & $15,62 \mathrm{C}$ & $32,90 \mathrm{~B}$ & $36,40 \mathrm{~B}$ & $64,56 \mathrm{C}$ \\
\hline
\end{tabular}

Em que: ${ }^{1}$ As amostras receberam os produtos de acabamentos, mas ainda não foram submetidas à radiação ultravioleta. Os valores assinalados com a mesma letra dentro de cada coluna dos parâmetros colorimétricos, para cada tratamento, não diferem entre si ao nível de $1 \%$ de probabilidade pelo Teste de Tukey. 


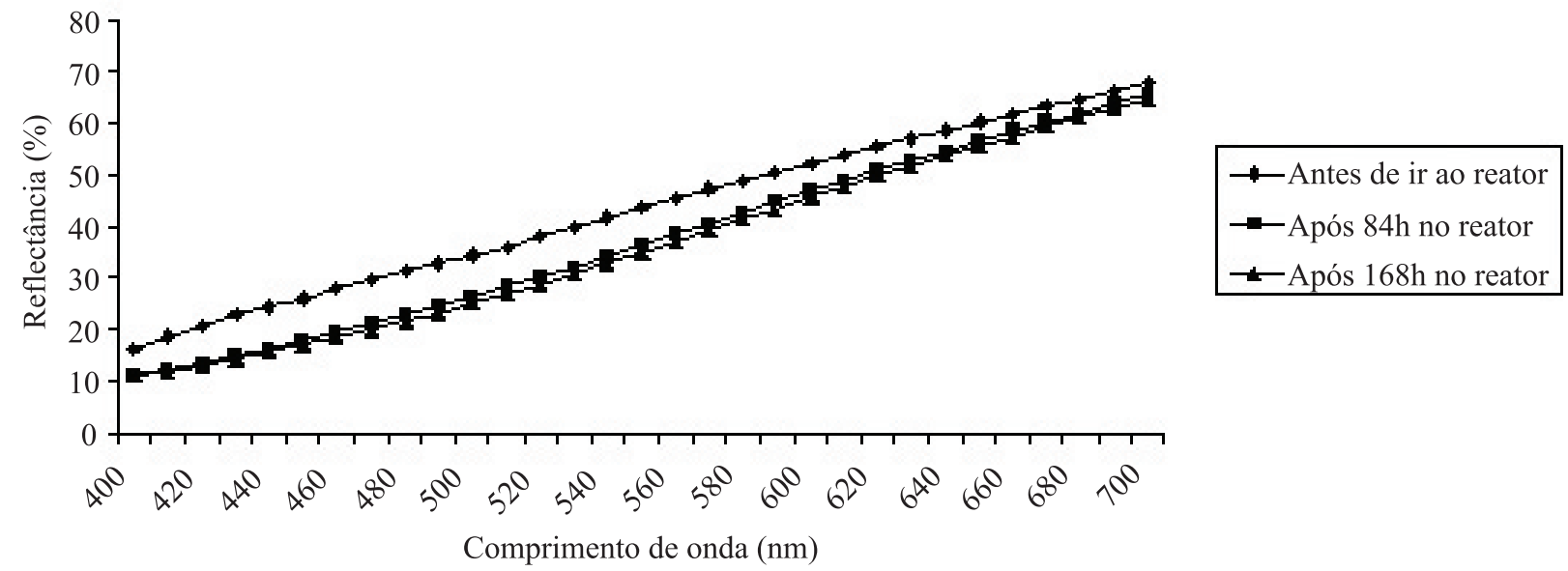

FIGURA 1: Espectros de refletância médios das amostras da madeira testemunha.

FIGURE 1: Average reflectance spectra of control samples of wood.

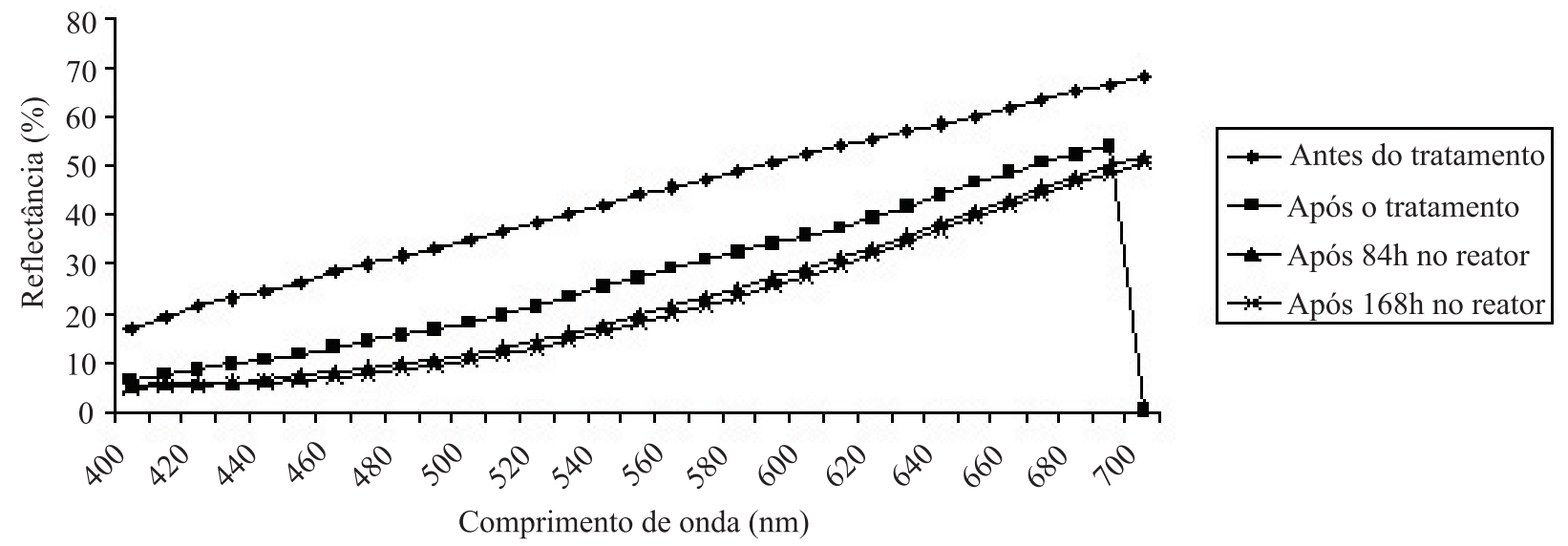

FIGURA 2: Espectros de refletância médios das amostras da madeira tratada com seladora (nitrocelulose) FIGURE 2: Average reflectance spectra of samples of wood treated with sealer (nitrocellulose).

A figura 3 mostra as curvas de refletância do tratamento com polisten nos diversos tempos de irradiações ultravioletas. A madeira tratada com o polisten e submetida a radiações ultravioletas não mostra alteração significativa em sua cor. Os parâmetros colorimétricos $\left(\mathrm{L}^{*}, \mathrm{a}^{*}, \mathrm{~b}^{*}\right.$ e por consequência $\mathrm{C}$ e $\mathrm{h}^{*}$ ) não apresentam diferenças significativas. A incidência dos raios UV durante as 84 e 168 horas não modificaram a coloração superficial da madeira. Isso era esperado na radiação de 84 horas, uma vez que esse produto possui filtro solar em sua composição química. Já para a radiação mais prolongada (168 horas), a permanência da estabilidade da cor constata a durabilidade do produto, provavelmente em função eficiência do seu filtro ter permanecido por períodos mais prolongados. Entretanto, vale ressaltar que, com o passar do tempo, os produtos de acabamentos vão se degradando, deixando a madeira sem proteção, podendo acarretar em alteração da cor. É importante conhecer as propriedades de cada produto quanto à sua proteção à descoloração da madeira e às consequências de sua aplicação para a cor da madeira.

As amostras que foram tratadas com produto de acabamento sofreram alteração de suas curvas espectrais originais. Observa-se um escurecimento em ambos os tratamentos, isso em conseqüência das características do produto impregnado. No tratamento com polisten o escurecimento foi maior. Foram observados em ambos os tratamentos que, na região do azul (400$560 \mathrm{~nm}$ ), há uma intensidade de refletância menor e aumentam continuamente até atingirem os valores máximos na faixa dominante do vermelho (após $600 \mathrm{~nm})$.

Ci. Fl., v. 20, n. 4, out.-dez., 2010 


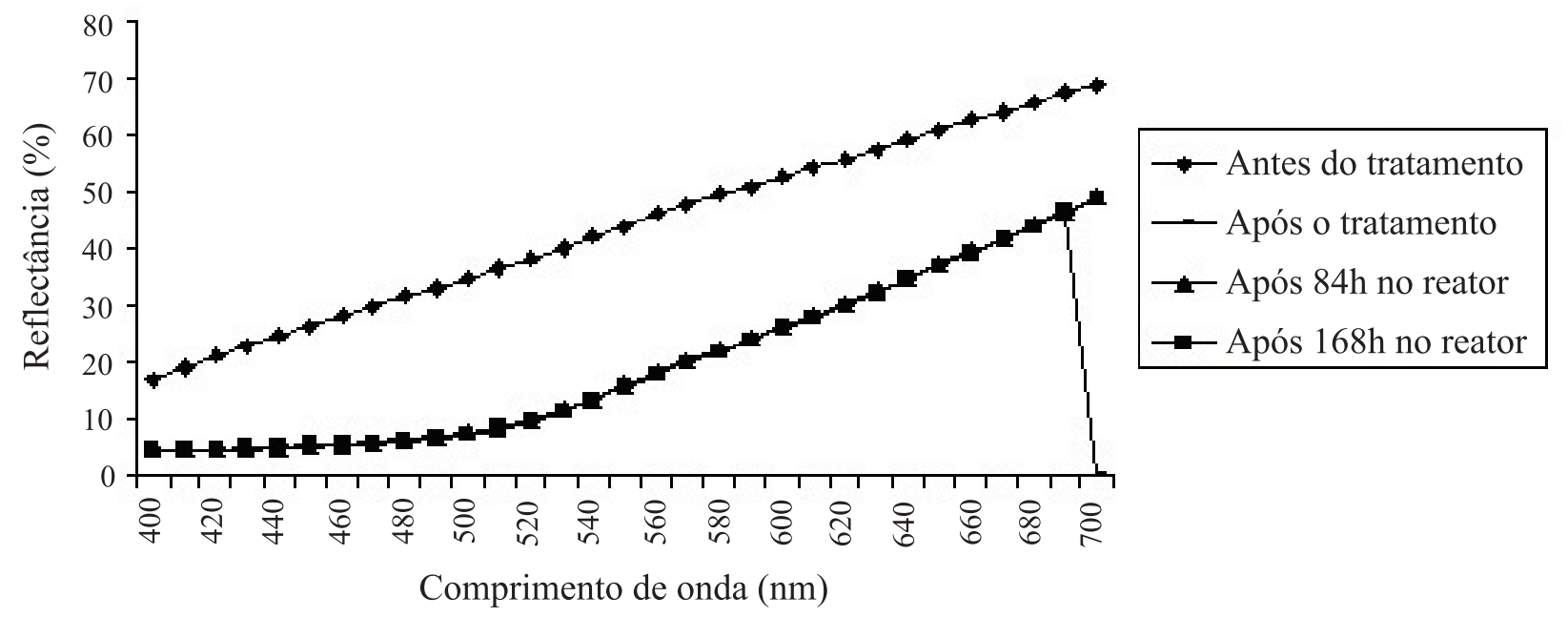

FIGURA 3: Espectros de refletância médios das amostras da madeira tratada com polisten

FIGURE 3: Average reflectance spectra of samples of wood treated with polisten.

\section{Parâmetro $\Delta \mathbf{E}$}

$\mathrm{O}$ parâmetro $\Delta \mathrm{E}$ combina as variáveis $L^{*}, a^{*}$ e b* em um único parâmetro, mensurando a alteração da cor de um material antes e depois de um determinado tratamento, conforme mencionado na metodologia deste trabalho.

A tabela 3 apresenta os valores médios de $(\Delta \mathrm{E})$ da madeira de freijó para cada tipo de tratamento submetidos a tempos diferentes de radiações ultravioletas.

Observando-se a tabela 3 , verifica-se que o tratamento com seladora foi o que mais alterou a cor da madeira, tanto no tempo de 84 horas como após 168 horas, quando comparado com o tratamento com polisten. É interessante observar que a testemunha sofre alteração em sua cor semelhante ao da seladora no tempo de 84 horas e menor que esta no tempo de radiação de 168 horas. Isso mostra

TABELA 3: Valores médios do parâmetro $\Delta \mathrm{E}$ da madeira de freijó para cada tipo de tratamento.

TABLE 3: Mean values of the parameter $\Delta \mathrm{E}$ of Freijó wood for each type of treatment.

\begin{tabular}{ccc}
\hline Tratamento & $\Delta \mathrm{E} 84$ horas & $\Delta \mathrm{E} 168$ horas \\
\hline Testemunha & $8,23 \mathrm{a}$ & $1,23 \mathrm{a}$ \\
Polisten & $0,47 \mathrm{~b}$ & $0,70 \mathrm{~b}$ \\
Seladora & $8,49 \mathrm{a}$ & $2,05 \mathrm{c}$ \\
\hline
\end{tabular}

Em que: Os valores assinalados com a mesma letra, na mesma coluna, dentro de cada tempo de radiação, não diferem entre si ao nível de $1 \%$ de significância pelo teste de Tukey. que a madeira tratada com seladora deverá, de tempo em tempo, receber demão desse produto para tentar manter a coloração inicial da primeira demão. A madeira tratada com polisten apresenta-se como a mais estável com o passar do tempo, confirmando os resultados da tabela 2. A testemunha, depois de um tempo, tende a estabilizar a sua cor, geralmente mais escura que a cor inicial.

\section{CONCLUSÕES}

A espectrocolorimetria é uma ferramenta importante para monitorar o processo de fotodegradação da madeira. O envelhecimento artificial acelerado permite ter uma idéia do comportamento da cor de uma madeira, com o passar do tempo, sob ação de produtos de acabamentos.

A madeira de freijó (Cordia goeldiana Huber) é caracterizada pela coordenada $b^{*}$ (pigmentação amarela) e pela claridade ( $\left.\mathrm{L}^{*}\right)$. Por outro lado, o envelhecimento da madeira, em seu estado natural, é detectado sobretudo pela coordenada a* (pigmento vermelho), levando a um escurecimento desta.

Os produtos de acabamentos utilizados nesta pesquisa alteraram a cor natural da madeira. Tanto o polisten como a seladora, logo após suas aplicações, escureceram a madeira. $\mathrm{O}$ envelhecimento dessa madeira quando tratada com seladora continua modificando a sua cor com o passar do tempo. $\mathrm{O}$ produto polisten, depois de aplicado à madeira, conserva a cor para os períodos de envelhecimentos simulados na pesquisa. 
Sugere-se, para as próximas pesquisas, fazer uma análise química da madeira e dos produtos de acabamentos tentando identificar seus componentes para melhor entender o comportamento da cor e de suas implicações.

\section{AGRADECIMENTOS}

Ao Laboratório de Materiais e Combustíveis do Instituto de Química da Universidade de Brasília, pelo apoio a este trabalho, permitindo a utilização do reator.

Ao Laboratório de Produtos Florestais/SFB que permitiu a utilização do espectrofotômetro.

\section{REFERÊNCIAS BIBLIOGRÁFICAS}

AYADI, N. et al. Color stability of heat-treated woos during artificial weathering. Holz als Rohund Werkstoff, Berlin, Heidelberg, v. 61, n. 3, p. 221-226, jun.2003.

CAMARGOS, J.A.A. Colorimetria quantitativa aplicada na elaboração de uma tabela de cores para madeiras tropicais. Brasília, 1999. $99 \mathrm{f}$. Dissertação (Mestrado em Ciências Florestais)Universidade de Brasília, Brasília, 1999.

CHANG, S.-T. et al. Photodegradation and photoprotection os wood surfaces. Wood and fiber, v. 14, n. 2, p. 104-107. 1982.

CHANG, H.-T. et al. Correlation between softwood discoloration induced by accelerated lightfastness testing and by indoor exposure. Polymer Degradation and Stability. n. 72 , p. $361-365$. 2001.

FEIST, W.C. Weathering and protection of wood. In: Annual Meeting of the American Wood-Preservers' Association, 79, 1983, Kansas City. Proceedings. p. 195-205.

GEORGE, B. et al. Photodegradation and photostabilisation of wood - the state of the art. Polymer Degradation and Stability, v. 88. p. 268274. 2005.

HON, D. N.-S Weathering and photochemistry of wood. In: Hon, D.N.-S; Shiraishi, N. Woos and cellulosic chemistry. $2^{\text {nd }}$ ed. New york: Marcel Dekker, 2001. 928 p.

MITSUI, K. et al. Low atmospheric temperature dependence on photodegradation of wood. Journal of Photochemistry and Photobiology B: Biology. v. 81, p. 84-88. 2005.

NEUMANN, M. G. et al. A fotoquímica no Brasil. Quim. Nova, v. 25, p. 34-38, 2002. Supl. 1.

OLIVEIRA, F.C.C. Modelos de calibração multivariada associados à espectroscopia vibracional para análise de misturas diesel óleos vegetais. Brasília, 2006. 98 f. Dissertação (Instituto de Química)-Universidade de Brasília, Brasília, 2006.

SILVA, J. O. et al. Fotodecomposição e proteção de madeiras tropicais. Floresta e Ambiente, Rio de Janeiro, v. 11, n. 2, p. 07 - 13. ago/dez. 2004.

SILVA, J. O. et al. Resistência ao intemperismo artificial de cinco madeiras tropicais e de dois produtos de acabamento. Ciência Florestal, Santa Maria, v. 17, n. 1, p. 17 - 23. 2007.

TEMIZ, A. et al. Surface roughness and color characteristics of wood treated with preservatives after accelerated weathering test. Applied Surface Cience, n. 205, p. 35-42. 2005.

TOLVAJ, L. Discoloration and deterioration of wood surface by ultraviolet light. In: Wood Structure and Properties'94 - The $2^{\text {nd }}$ International Symposium, Zvolen-Slovakia, 1994, p.181-189. 